\title{
BURDEN OPTIMISATION OF LUMP CHARGE MATERIALS FOR FOUNDRY FURNACES
}

Calculation of economically optimum charge burden for foundry furnaces depends on a solution that can be found in the field of mathematical linear programming. A traditional linear optimisation method means looking for continuous variables that can define portion of every charge component.

Sometimes, it can be observed that a calculated portion of charge material with a defined lump mass is rounded up, which is wrong because the charge burden prepared in such a way may either show a mistaken chemical composition, or it can entail a significant cost. With charge materials characterised by defined mass lumps, it is recommended to use a modified method of integer linear optimisation.

This article contains definitions of a goal function and a system of constraints considering the charge materials as stated above. In addition, a sample calculation has been included hereto to show such optimisation for a selected process of metal melting in a casting furnace.

Keywords: burden of lump chargé materials

\section{Introduction}

The usual procedure applied during optimisation of the cheapest charge burden for foundry furnaces depends on establishing a precise proportion of every charge material $x_{j}$, so that the goal function as given below [1-3]

$$
\sum_{j=1}^{N} c_{j} x_{j}
$$

can reach its minimum while the following constraints are imposed:

$$
\left\{\begin{array}{c}
\sum_{j=1}^{N} A_{i j} x_{j} \geq A_{i}^{d} m_{w} \\
\sum_{j=1}^{N} A_{i j} x_{j} \leq A_{i}^{g} m_{w} \\
0 \leq x_{j}^{d} \leq x_{j} \leq x_{j}^{g} \leq m_{w} \\
\sum_{j=1}^{N} x_{j}=m_{w} \\
i=1,2, \ldots, M
\end{array}\right.
$$

where:

$N$ - number of charge materials,

$c_{j}-$ unit price of the $j$-th charge component, for example $€ / \mathrm{kg}$, $x_{j}-$ mass fraction of the $j$-th charge material, $\mathrm{kg}$,

$A_{i j}$ - content of $i$-th element in the $j$-th charge component, $\%$,

$A_{i}{ }^{d}, A_{i}^{g}-$ lower and upper level of $i$-th element content in the calculated charge material, $\%$,

$m_{w}$ - weight of the calculated charge material, $\mathrm{kg}$,

$x_{j}^{d}, x_{j}^{g}-$ lower and upper limit of the content of the $j$-th component in the charge material, $\mathrm{kg}$,

$M$ - number of chemical elements.

Considering that a goal function and a system of constraints are exclusively expressed as linear functions, the task can be solved by adopting a selected method of linear programming like, for example, method simple $x$ [4]. Variables $x_{j}$ are continuous variables in this example. Calculation of charge burden using initial data as given in Table 1, can be an example task including such variables.

In this example, linear programming helps to calculate quality proportions $x_{j}(j=1,2, \ldots, 8)$ in such a way that a goal function as given here:

$$
\begin{aligned}
& 0,40 x_{1}+0,27 x_{2}+0,25 x_{3}+0,45 x_{4}+ \\
& +1,30 x_{5}+0,98 x_{6}+0,49 x_{7}+5,00 x_{8}
\end{aligned}
$$

can reach its minimum value under the constraints:

\footnotetext{
AGH UNIVERSITY OF SCIENCE AND TECHNOLOGY, FACULTY OF FOUNDRY ENGINEERING, 23 REYMONTA STR., 30-059 KRAKOW, POLAND
} 
Chemical composition, cost, constraints and final weight of the charge materials

\begin{tabular}{|c|c|c|c|c|c|c|c|c|c|}
\hline \multirow{2}{*}{\multicolumn{2}{|c|}{ Material }} & \multicolumn{6}{|c|}{ Chemical composition } & \multirow{2}{*}{$\begin{array}{l}\text { Cost } \\
€ / \mathbf{k g} \\
\end{array}$} & \multirow{2}{*}{$\begin{array}{c}\text { Limit } \\
\text { kg }\end{array}$} \\
\hline & & C & Si & Mn & $\mathbf{P}$ & S & $\mathrm{Cu}$ & & \\
\hline$x_{1}$ & Pig iron & 4,30 & 0,75 & 0,43 & 0,03 & 0,02 & & 0,40 & $\geq 200$ \\
\hline$x_{2}$ & Iron scrap & 2,80 & 1,60 & 0,50 & 0,04 & 0,03 & 0,35 & 0,27 & $\leq 1200$ \\
\hline$x_{3}$ & Steel scrap & 0,35 & 0,20 & 0,20 & 0,01 & 0,03 & & 0,25 & \\
\hline$x_{4}$ & Sphero scrap & 3,50 & 2,40 & 0,75 & 0,04 & 0,02 & & 0,45 & $\geq 250$ \\
\hline$x_{5}$ & $\mathrm{FeSi}$ & 0,12 & 68,00 & & & & & 1,30 & \\
\hline$x_{6}$ & FeMn & 6,40 & 1,00 & 77,00 & & & & 0,98 & \\
\hline$x_{7}$ & $\mathrm{SiC}$ & 29,00 & 59,00 & & & & & 0,49 & \\
\hline$x_{8}$ & $\mathrm{Cu}$ & & & & & & 99,00 & 5,00 & \\
\hline \multicolumn{2}{|c|}{ Final charge } & $3,10 \div 3,30$ & $1,65 \div 1,85$ & $0,65 \div 0,80$ & $\max .0,10$ & $\max .0,08$ & $0,50 \div 0,70$ & \multicolumn{2}{|c|}{$m_{w}=3200 \mathrm{~kg}$} \\
\hline
\end{tabular}

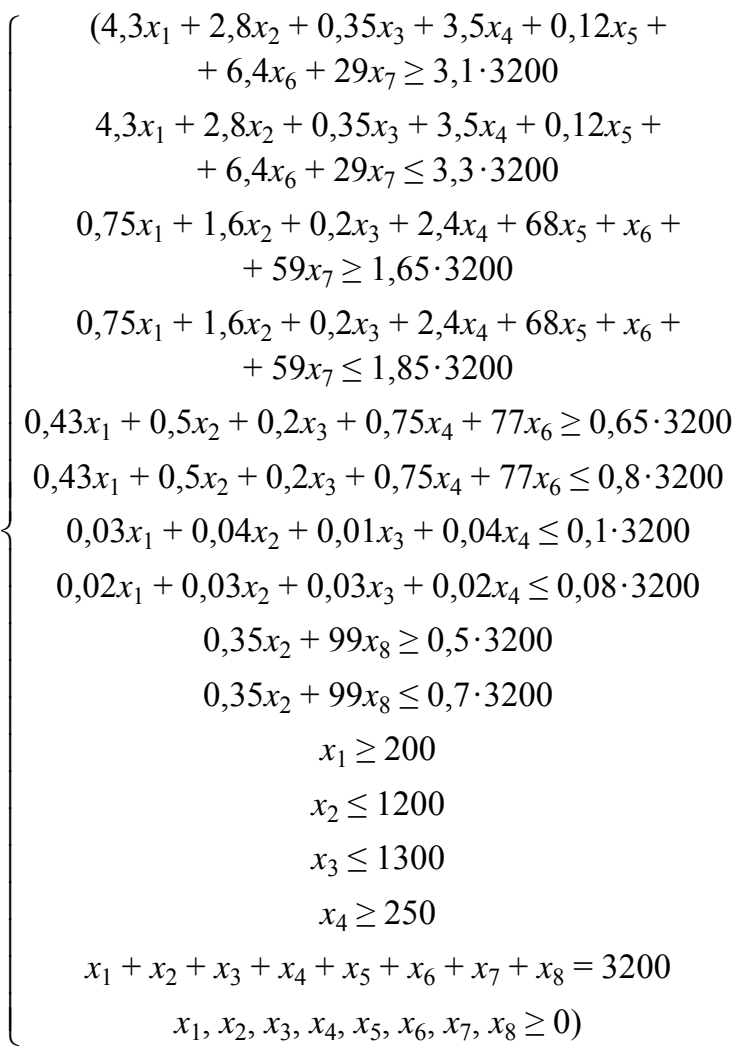

The solution of linear optimisation task (3)-(4) is provided in Table 2.

TABLE 2

Charge burden for input data included in Table 1

\begin{tabular}{|c|c|c|c|}
\hline \multicolumn{2}{|c|}{ Material } & Weight, kg & Chemical Constitution \\
\hline$x_{1}$ & Pig iron & 960,186 & \multirow{6}{*}{$\begin{array}{c}\mathrm{C}=3,10 \%, \mathrm{Si}=1,85 \% \\
\mathrm{Mn}=0,65 \%, \mathrm{P}=0,03 \% \\
\mathrm{~S}=0,03 \%, \mathrm{Cu}=0,50 \%\end{array}$} \\
\hline$x_{2}$ & Iron scrap & 1200,000 & \\
\hline$x_{3}$ & Steel scrap & 725,555 & \\
\hline$x_{4}$ & Sphero scrap & 250,000 & \\
\hline$x_{5}$ & $\mathrm{FeSi}$ & 0,000 & \\
\hline$x_{6}$ & FeMn & 9,540 & \\
\hline$x_{7}$ & $\mathrm{SiC}$ & 42,800 & \multirow{2}{*}{ Cost $=0,34 € / \mathrm{kg}$} \\
\hline$x_{8}$ & $\mathrm{Cu}$ & 11,919 & \\
\hline
\end{tabular}

The charge burden as presented in Table 2 will constitute a basis for further calculations and comparisons.

\section{Algorithm for charge burden optimisation when using defined lump mass materials}

In foundry manufacturing, some charge materials like pig iron and ferrous alloys appearing in the form of ingots, batches of steel plates or shavings briquettes are characterised by determined weight of their lumps.

It has to be underlined that rounding up of the results of continuous linear optimisation to the closest full mass iteration of a defined component lump, may lead to deviations like inappropriate chemical composition of the charge burden or higher cost as compared to another material that fulfils all the accepted objectives.

If, for example, along with the data shown in Table 1, weight of particular bits of materials is introduced according to Table 3 , that can bring a result of appropriate rounding up of calculation scores from Table 2, and, consequently, it can be possible to achieve charge burden calculation as shown in Table 4 .

TABLE 3

Assumed mass of selected charge materials lumps

\begin{tabular}{|c|c|c|}
\hline \hline \multicolumn{2}{|c|}{ Material } & Mass of single lump, kg \\
\hline$x_{1}$ & Pig iron & 15 \\
\hline$x_{3}$ & Steel scrap & 20 \\
\hline$x_{5}$ & FeSi & 1 \\
\hline$x_{6}$ & FeMn & 2 \\
\hline$x_{7}$ & SiC (bag) & 25 \\
\hline
\end{tabular}

TABLE 4

Charge burden calculation based on the input data from Table 1 and Table 3 and rounded up portions values of selected materials

\begin{tabular}{|c|c|c|c|}
\hline \multicolumn{2}{|r|}{ Material } & Weight, kg & Chemical Constitution \\
\hline$x_{1}$ & Pig iron & 960 & \multirow{6}{*}{$\begin{array}{c}\mathrm{C}=3,16 \%, \mathrm{Si}=1,98 \% \\
\mathrm{Mn}=0,66 \%, \mathrm{P}=0,03 \% \\
\mathrm{~S}=0,03 \%, \mathrm{Cu}=0,47 \%\end{array}$} \\
\hline$x_{2}$ & Iron scrap & 1199 & \\
\hline$x_{3}$ & Steel scrap & 720 & \\
\hline$x_{4}$ & Sphero scrap & 250 & \\
\hline$x_{5}$ & $\mathrm{FeSi}$ & 0 & \\
\hline$x_{6}$ & FeMn & 10 & \\
\hline$x_{7}$ & $\mathrm{SiC}$ & 50 & \multirow{2}{*}{ Cost $=0,34 € / \mathrm{kg}$} \\
\hline$x_{8}$ & $\mathrm{Cu}$ & 11 & \\
\hline
\end{tabular}


In the calculation shown in Table 4 the content of $\mathrm{Si}$ in the final charge is higher than the accepted levels as given in Table 1. Respectively, the content of $\mathrm{Cu}$ is lower.

Accepting index $k$, to mark a number of a charge component $(k \leq N)$ for which one lump weight will show $p_{k}$, the system of constraints can be defined as follows:

$$
\left\{\begin{array}{c}
\sum_{j=1}^{N} A_{i j} x_{j} \geq A_{i}^{d} m_{w} \\
\sum_{j=1}^{N} A_{i j} x_{j} \leq A_{i}^{g} m_{w} \\
0 \leq x_{j}^{d} \leq x_{j} \leq x_{j}^{g} \leq m_{w} \\
x_{k} \bmod p_{k}=0 \\
\sum_{j=1}^{N} x_{j}=m_{w} \\
i=1,2, \ldots, M \\
1 \leq k \leq N
\end{array}\right.
$$

The optimisation task comes down to setting down such fractions proportions $x_{j}$, that the goal function (1) is minimised under the constraints (5).

The problem can be solved by adopting a branch and bound method.

Considering that different values can be displayed in $p_{k}$, like the ones shown in Table 3, the branch and bound method requires some modification where a key factor will be an order in which variables $x_{k}$ will be chosen for particular stages of division and constraints modification process.

\section{Calculation example}

Based on the input data contained in Tables 1 and 3, optimisation of charge burden lies in designating appropriate values $x_{j}$ so that the goal function is minimum under the following constraints:

$$
\left\{\begin{array}{c}
\left(4,3 x_{1}+2,8 x_{2}+0,35 x_{3}+3,5 x_{4}+0,12 x_{5}+\right. \\
+6,4 x_{6}+29 x_{7} \geq 3,1 \cdot 3200 \\
4,3 x_{1}+2,8 x_{2}+0,35 x_{3}+3,5 x_{4}+0,12 x_{5}+ \\
+6,4 x_{6}+29 x_{7} \leq 3,3 \cdot 3200 \\
0,75 x_{1}+1,6 x_{2}+0,2 x_{3}+2,4 x_{4}+68 x_{5}+ \\
+x_{6}+59 x_{7} \geq 1,65 \cdot 3200 \\
0,75 x_{1}+1,6 x_{2}+0,2 x_{3}+2,4 x_{4}+68 x_{5}+ \\
+x_{6}+59 x_{7} \leq 1,85 \cdot 3200 \\
0,43 x_{1}+0,5 x_{2}+0,2 x_{3}+0,75 x_{4}+77 x_{6} \geq 0,65 \cdot 3200 \\
0,43 x_{1}+0,5 x_{2}+0,2 x_{3}+0,75 x_{4}+77 x_{6} \leq 0,8 \cdot 3200 \\
0,03 x_{1}+0,04 x_{2}+0,01 x_{3}+0,04 x_{4} \leq 0,1 \cdot 3200 \\
0,02 x_{1}+0,03 x_{2}+0,03 x_{3}+0,02 x_{4} \leq 0,08 \cdot 3200 \\
0,35 x_{2}+99 x_{8} \geq 0,5 \cdot 3200 \\
0,35 x_{2}+99 x_{8} \leq 0,7 \cdot 3200
\end{array}\right.
$$

$$
\begin{gathered}
x_{1} \geq 200 \\
x_{2} \leq 1200 \\
x_{3} \leq 1300 \\
x_{4} \geq 250 \\
x_{1} \bmod 15=0 \\
x_{3} \bmod 20=0 \\
x_{5} \bmod 1=0 \\
x_{6} \bmod 2=0 \\
x_{7} \bmod 25=0 \\
x_{1}+x_{2}+x_{3}+x_{4}+x_{5}+x_{6}+x_{7}+x_{8}=3200 \\
\left.x_{1}, x_{2}, x_{3}, x_{4}, x_{5}, x_{6}, x_{7}, x_{8} \geq 0\right)
\end{gathered}
$$

\begin{tabular}{|c|c|c|c|c|}
\hline & \multicolumn{4}{|c|}{ Optimisation task } \\
\hline & \multicolumn{4}{|c|}{ variable $x_{7}$} \\
\hline & \multicolumn{2}{|c|}{ P1 } & \multicolumn{2}{|c|}{ P2 } \\
\hline System of constraints & \multicolumn{2}{|c|}{$\begin{array}{c}(6) \\
x_{7} \leq 25\end{array}$} & \multicolumn{2}{|c|}{$\begin{array}{c}(6) \\
x_{7} \geq 50\end{array}$} \\
\hline \multirow{8}{*}{ Charge burden } & $x_{1}$ & 1090,23 & $x_{1}$ & 1137,66 \\
\hline & $x_{2}$ & 1200,00 & $x_{2}$ & 827,54 \\
\hline & $x_{3}$ & 608,79 & $x_{3}$ & 911,08 \\
\hline & $x_{4}$ & 250,00 & $x_{4}$ & 250,00 \\
\hline & $x_{5}$ & 4,94 & $x_{5}$ & 0,00 \\
\hline & $x_{6}$ & 9,12 & $x_{6}$ & 10,48 \\
\hline & $x_{7}$ & 25,00 & $x_{7}$ & 50,00 \\
\hline & $x_{8}$ & 11,92 & $x_{8}$ & 13,24 \\
\hline Cost of charge, $€ / \mathrm{kg}$ & \multicolumn{2}{|c|}{0,35070} & \multicolumn{2}{|c|}{0,35300} \\
\hline
\end{tabular}

In the first calculation stage, a task is to be solved using continuous variables $x_{j}$ as defined by functions (3) and (4). The results of this stage can be found in Table 2 .

Using a branch and bound algorithm, along with a variable $x_{7}$ that has the biggest lump mass value $(25 \mathrm{~kg})$, the aim is to solve two optimisation tasks P1 and P2 which include an expanded system of constraints (6) according to Table 5, keeping the same goal function (3).

Continuous variable $x_{7}=42,8 \mathrm{~kg}$, hence in task P1 inequality $x_{7} \leq 25$ has to be added, whereas in task P2, the inequality to be added is $x_{7} \geq 50$.

TABLE 5

Tasks $\mathrm{P} 1$ and $\mathrm{P} 2$ - results

As the charge cost in task P1 is lower than in task P2, according to the branch and bound algorithm, the next step should be two subsequent tasks which necessitate adding to the system of constraints from task P1 either the inequality $x_{3} \leq 600 \mathrm{~kg}$ (task P3), or the inequality $x_{3} \geq 620 \mathrm{~kg}$ (task P4). The calculation results of the tasks $\mathrm{P} 3$ and $\mathrm{P} 4$, where variable $x_{1}$ is considered, have been shown in Table 6 .

The calculation results of the tasks from P7 to P10, where variables $x_{6}$ i $x_{5}$ are considered, have been shown in Table 7.

In task P10, variable $x_{7}$ is not a whole multiple of $25 \mathrm{~kg}$, hence optimisation P11 has to be carried out under condition 
Tasks P3, P4, P5 and P6 - results

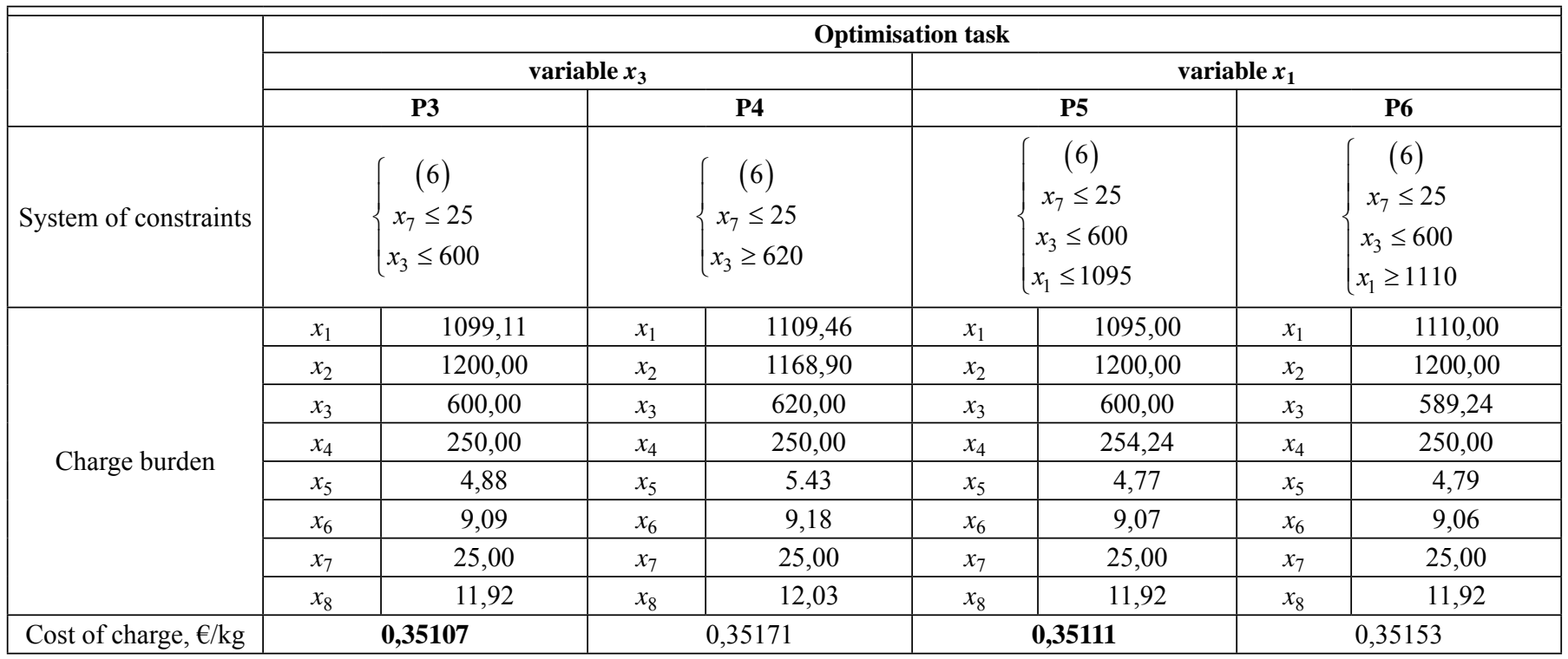

TABLE 7

Task P7, P8, P9 and P10 - results

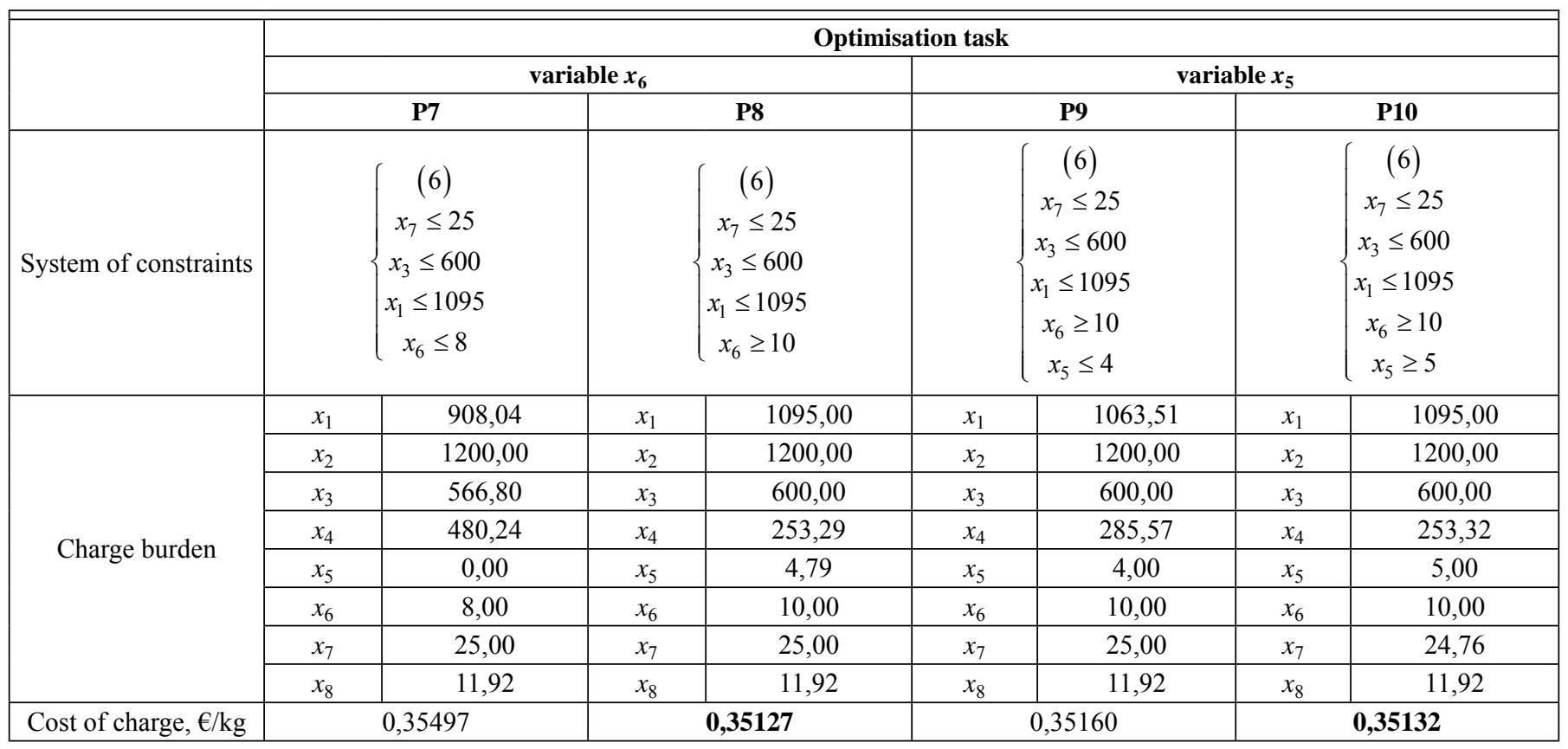

$x_{7} \leq 0$, and optimisation $\mathrm{P} 12$ under condition $x_{7} \geq 25$. The results of these calculations have been presented in Table 8 .

In task P12 all the required variables are full multiples of defined weight of the lumps. Therefore, it is finally the optimum charge burden with parameters as shown in Table 9.

The charge burden as presented in Table 9 is considerably different from the one (Fig. 1) achieved due to continuous linear optimisation (Table 2) apart from the price which in the first case, is slightly higher.

\section{Summary}

A modified model for charge burden optimisation for casting furnaces which has been presented in this article can help improve technological precision aspects of smelting processes thanks to accepting the idea of using charge materials with defined lump weight.

The modified branch and bound algorithm, known in the theory of integer linear programming, enables effective designation of charge components proportions while using different forms of charge materials (lumps, briquettes, ingots, loose or granular products). 


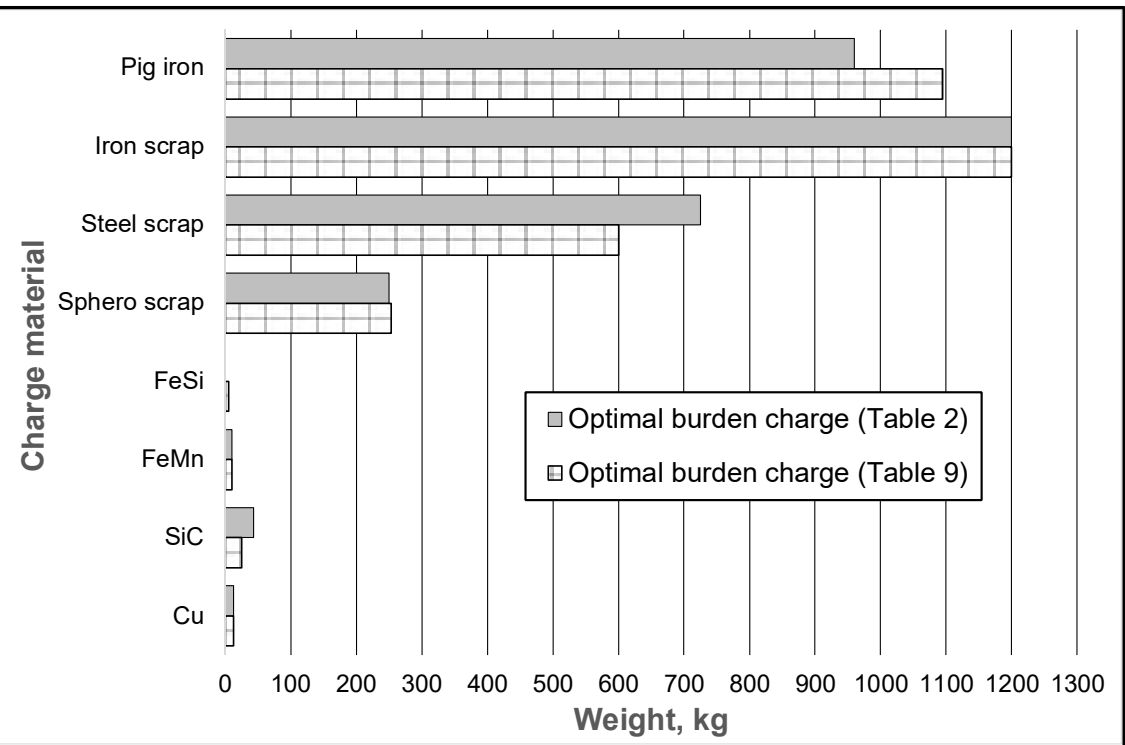

Fig. 1. Comparison of the optimization results using two different calculation methods: burden charge with continuous values (Table 2) and burden charge with lump materials (Table 9)

TABLE 9

Task P11 and P12 - results

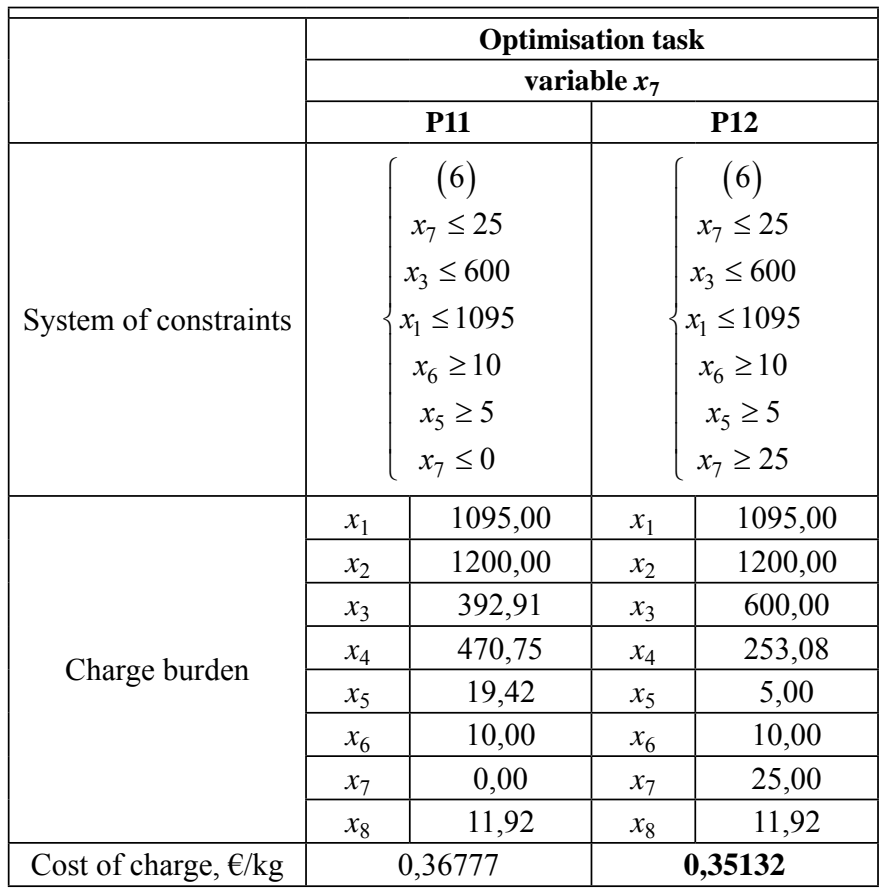

\section{Acknowledgements}

The study was co-financed by AGH as a targeted project No. 11.11.170.318-6
The optimum charge burden for the selected charge materials lump weight

\begin{tabular}{|c|c|c|c|}
\hline \multicolumn{2}{|c|}{ Material } & Weight, kg & Chemical Constitution \\
\hline$x_{1}$ & Pig iron & 1095,00 & \multirow{6}{*}{$\begin{array}{c}\mathrm{C}=3,11 \%, \mathrm{Si}=1,65 \% \\
\mathrm{Mn}=0,67 \%, \mathrm{P}=0,03 \% \\
\mathrm{~S}=0,03 \%, \mathrm{Cu}=0,50 \%\end{array}$} \\
\hline$x_{2}$ & Iron scrap & 1200,00 & \\
\hline$x_{3}$ & Steel scrap & 600,00 & \\
\hline$x_{4}$ & Sphero scrap & 253,08 & \\
\hline$x_{5}$ & $\mathrm{FeSi}$ & 5,00 & \\
\hline$x_{6}$ & FeMn & 10,00 & \\
\hline$x_{7}$ & $\mathrm{SiC}$ & 25,00 & \multirow{2}{*}{ Cost $=0,35 € / \mathrm{kg}$} \\
\hline$x_{8}$ & $\mathrm{Cu}$ & 11,92 & \\
\hline
\end{tabular}

\section{REFERENCES}

[1] E. Ziółkowski, Algorithms of furnace charge burden optimization in foundries, Archives of Metallurgy and Materials 52, 3, 487-495 (2007).

[2] E. Ziółkowski, Methods review for the determination of burden for foundry furnaces, Archives of Foundry Engineering, ISBN: 978-83-929266-0-3, 449-460 (2009).

[3] E. Ziółkowski, Algorithm for burden calculation for foundry furnaces using charge materials with an uncertain composition, Archives of Metallurgy and Materials 58, 3, 887-889 (2013).

[4] S.I. Gass, Linear Programming: Methods and Applications, Courier Corporation (2003). 